\title{
Ionic Conductivity of Polymeric Solid Electrolytes Based on Poly(propylene oxide) or Poly(tetramethylene oxide)
}

\author{
Masayoshi WATANABE, Katsuro NAGAOKA, \\ Motoi KANBA, and Isao SHINOHARA \\ Department of Polymer Chemistry, Waseda University, \\ Ohkubo, Shinjuku-ku, Tokyo 160, Japan
}

(Received June 17, 1982)

\begin{abstract}
The electrical properties of certain polymeric solid electrolytes were studied. The polymeric solid electrolytes were prepared by dissolving several kinds of salts into the polycation matrix containing poly(propylene oxide) (PPO) or poly(tetramethylene oxide) (PTMO) segment in the main chain. The electrical conductivity at $20^{\circ} \mathrm{C}$ and the activation energy for conduction ranged from $10^{-7}$ to $10^{-10} \mathrm{~S} \mathrm{~cm}^{-1}$ and from 8 to $16 \mathrm{kcal} \mathrm{mol}^{-1}$, respectively, being dependent on the salt concentration, the salt species, the PPO segment size and the structure of the polyether segment. The ionic character of the electrical conductivity was demonstrated. Higher conductivity was observed with an increase in the salt concentration, in the PPO segment size and in the sum of the cation and anion radii of the salt in the PPO based polymeric solid electrolytes. The effects of the ion radius on conductivity were divided into two classes with respect to dependence on the salt species. These effects were due to the difference in the dissolving state of the salts in the PPO segment. The conductivity of the PTMO based polymeric solid electrolytes was lower than that of the PPO based polymeric solid electrolytes. The activation energy was mainly influenced by the salt concentration, and little influence of the salt species and the size and structure of the polyether segment was observed.
\end{abstract}

KEY WORDS Polymeric Solid Electrolytes / Ionic Conductor / Polymeric

Solvent / Poly(propylene oxide)/Poly(tetramethylene oxide)/Conductivity /

Activation Energy /

The most commonly used ionic conductors are electrolyte solutions. In these solutions, solvents are limited to low molecular compounds. However, certain kinds of polymers are known to dissolve inorganic salts, forming homogeneous ioncontaining polymers. ${ }^{1-6}$ These ion-containing polymers are considered to be new electrolyte solutions in which polymeric materials functions as solvents. If fast ion transport is possible in the new electrolytes, polymeric solvents and their solution will open a new field in polymer science and electrochemistry.

Polyethers such as poly(ethylene oxide $)^{1}$ and poly(propylene oxide) $(\mathrm{PPO})^{2-5}$ are one type of polymeric solvents and dissolve many kinds of inorganic salts up to a high concentration. Especially, relatively low moleculr weight PPO is liquid at ambient temperature and can be treated as an ordinary solvent. We found that the electrolyte consisting of a PPO solution of various inorganic salts showed a high ionic conductivity of $10^{-4}$ $10^{-5} \mathrm{~S} \mathrm{~cm}^{-1}$ at ambient temperature. ${ }^{7}$ Studies on polymeric materials as ionic conductors have seldom been carried out up to the present. ${ }^{8}$ However, if these electrolyte solutions containing polymeric solvents can be solidified without decreasing the conductivity, polymeric solid electrolytes of high ionic conductivity can be obtained. The polymeric solid electrolytes will not only facilitate analysis of ion conductive behavior in polymers but also provide a new material having a wide range of application.

In this study, a polycation matrix containing a PPO segment in the main chain was synthesized. The polymeric solid electrolytes were prepared by 
dissolving several kinds of salt into the PPO segment. The effect of the PPO segment size, the salt concentration and the salt species on the ionic conductivity of the polymeric solid electrolytes were studied. Furthermore, the ionic conductivity of the polymeric solid electrolytes based on poly(tetramethylene oxide) (PTMO) was investigated.

\section{EXPERIMENTAL}

\section{Synthesis of Polycations}

Polycations were prepared by a procedure similar to that previously reported ${ }^{9}$ and so is described only briefly here. The molecular weight of hydroxytelechelic PPO was 1925 and 2880, and that of hydroxy-telechelic PTMO was 1970. Dimethylamino-terminated prepolymers were prepared by reacting these polyethers with tolylene-2,4-diisocyanate and $N, N$-dimethylaminoethanol sucessively. Afterwards, the prepolymers were extended by a stoichiometric amount of $p$-xylylenedichloride, using the Menschtkin reaction in methanol at $60^{\circ} \mathrm{C}$ for $100 \mathrm{~h}$ to obtain the polycations. The polycations obtained were purified by precipitation with diethylether. The results of the preparations and the abbreviations for the polycations are shown in Table I with the chemical structures of the samples. The polycations are elas- tic rubbery materials characterized by alternating structures of rigid polycation segments and the flexible polyether segments which contribute to the solvation of the ionic species.

\section{Preparation of Polymeric Solid Electrolytes}

Polymeric solid electrolytes were obtained as hybrid films by solvent casting. Each salt was dried in vacuo at $150^{\circ} \mathrm{C}$ for $16 \mathrm{~h}$ just before use. A preweighed amount of the polycation and the salt were dissolved in methanol for the preparation of PPO polycation and in pyridine for the PTMO polycation. This solution was cast onto a Teflon substrate, and the solvent was evaporated at $50^{\circ} \mathrm{C}$ for $24 \mathrm{~h}$ at ambient pressure and removed completely in vacuo at $80^{\circ} \mathrm{C}$ for $48 \mathrm{~h}$. It was confirmed that the solvent was completely removed from the hybrid films by measuring the weight of the hybrid films. The thickness of each hybrid film was $0.1-0.3 \mathrm{~mm}$. The utmost care was taken to prevent water sorption onto the films during film preparation.

\section{Electrical Measurements}

Figure 1 shows the apparatus for conductivity measurements and the cell construction. The sample for electrical measurement was cut from the films into disks of $1.0 \mathrm{~cm}$ in diameter and stacked between disk electrodes of $1.0 \mathrm{~cm}$ in diameter to form

Table I. Analytical results and structures of polycations

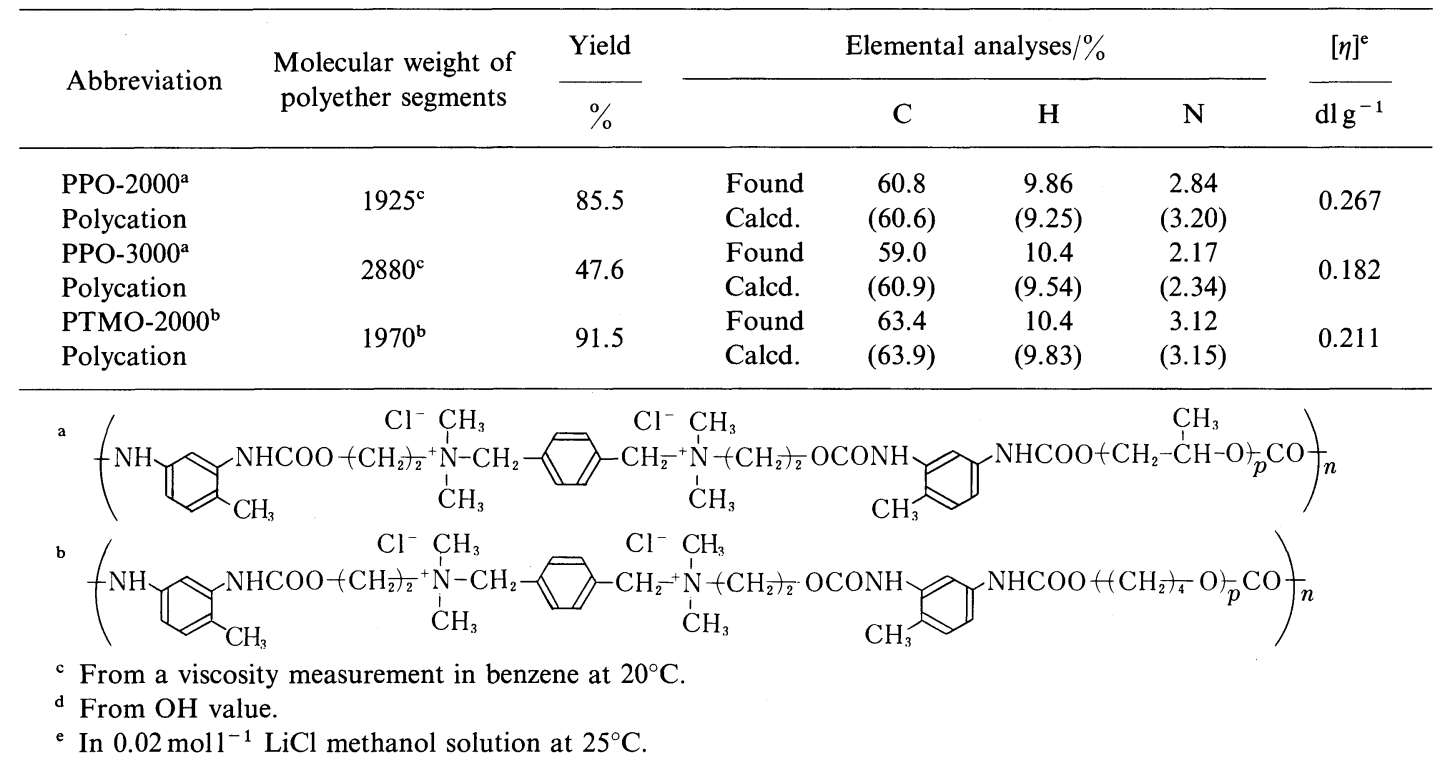




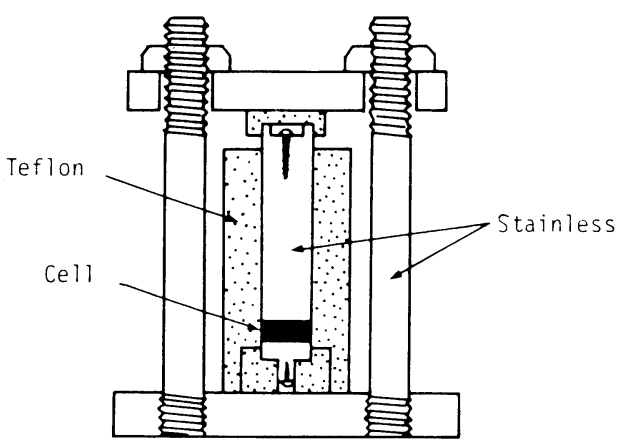

(a)

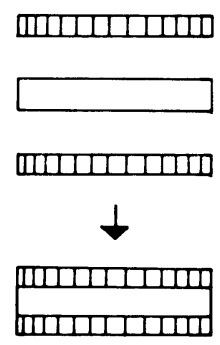

(b)

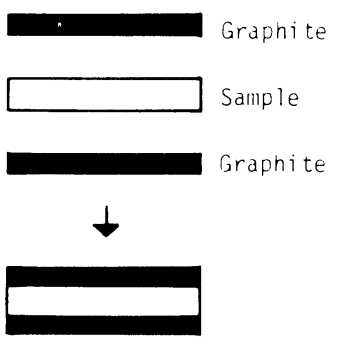

(c)

Figure 1. Apparatus for conductivity measurement and cell constructions: (a) apparatus for conductivity measurement; (b) cell for alternate current measurement; (c) cell for direct current measurement.

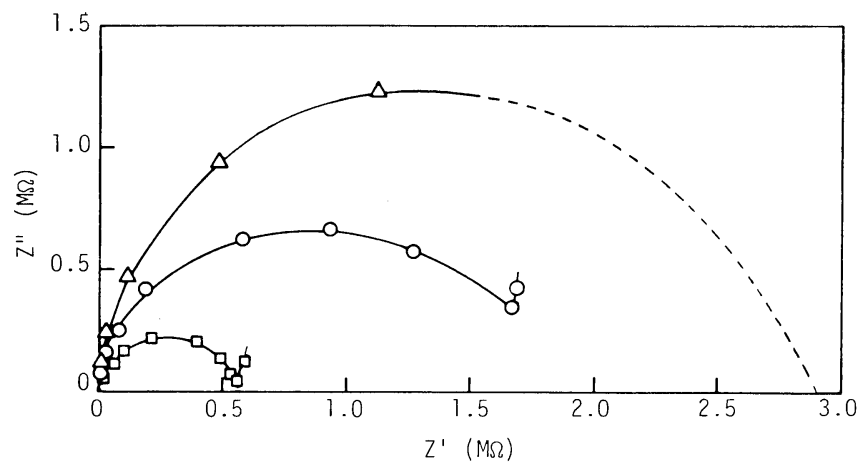

Figure 2. Complex impedance diagram for PPO polycation-salt hybrid films: $\square$, PPO-3000 polycation$\mathrm{LiClO}_{4}([$ Salt $] /[\mathrm{PO}$ unit $]=0.09 ; \bigcirc, \mathrm{PPO}-2000$ polycation-KSCN $([$ Salt $] /[\mathrm{PO}$ unit $]=0.09) ; \triangle$, PPO-3000 polycation $-\mathrm{LiClO}_{4}([\mathrm{Salt}] /[\mathrm{PO}$ unit $]=0.02)$.

a cell. The cell was encapsulated in a Teflon container having stainless terminals, as shown in Figure 1(a) and subjected to electrical measurement. The cell construction and electrical measurements were all made under a dry argon atmosphere.

The electrical conductivity was measured using the alternate current method ${ }^{10}$ with the cell,

$$
\mathrm{Pt} / \text { sample/Pt }
$$

as shown in Figure 1(b), so as to eliminate electrode polarization. The cell impedance was measured with a Yokogawa-Hewlett-Packard 4274A multi- 
frequency LCR meter from $10^{2}$ to $10^{5} \mathrm{~Hz}$ at an oscillation level of $1.0 \mathrm{~V}$. Figure 2 shows a typical complex impedance diagram of hybrid films. Actual resistance of the sample was estimated from the resistance $\left(Z^{\prime}\right)$ at which the reactance $\left(Z^{\prime \prime}\right)$ took on a minimum value. ${ }^{10}$ When the minimum of $Z^{\prime \prime}$ was not observed in the measured frequency range, real resistance was located at the point of intersection of the extrapolated semicircle of the complex impedance diagram with the $Z^{\prime}$ axis. ${ }^{10}$

The contribution of electronic conductivity to the electrical conductivity was investigated with the polarization cell, ${ }^{11}$

$$
\text { graphite/sample/graphite }
$$

as shown in Figure 1(c). The direct current through the cell at $1.0 \mathrm{~V}$ was detected with a Keithley $610 \mathrm{C}$ electrometer.

\section{Dynamic Mechanical Measurement}

Dynamic mechanical properties were measured with a Toyo Measuring Instruments Rheovibron

Table II. Electrical properties of polymeric solid electrolytes

\begin{tabular}{|c|c|c|c|c|c|}
\hline \multirow{2}{*}{ Polycation } & \multirow{2}{*}{ Salt } & [Salt] & \multirow{2}{*}{ 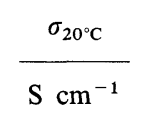 } & \multirow{2}{*}{ 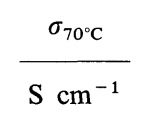 } & \multirow{2}{*}{$\frac{E_{\mathrm{a}}}{\mathrm{kcal} \mathrm{\textrm {mol } ^ { - 1 }}}$} \\
\hline & & [Polyether unit] & & & \\
\hline PPO-2000 & & 0 & $<10^{-12}$ & & \\
\hline \multirow[t]{14}{*}{ Polycation } & $\mathrm{LiClO}_{4}$ & 0.015 & $1.47 \times 10^{-9}$ & & \\
\hline & & 0.030 & $3.55 \times 10^{-9}$ & $8.18 \times 10^{-8}$ & 11.8 \\
\hline & & 0.045 & $7.43 \times 10^{-9}$ & $1.77 \times 10^{-7}$ & 13.8 \\
\hline & & 0.090 & $8.04 \times 10^{-9}$ & $3.69 \times 10^{-7}$ & 16.2 \\
\hline & $\mathrm{LiCl}$ & 0.090 & $2.75 \times 10^{-10}$ & & \\
\hline & $\mathrm{LiBr}$ & 0.090 & $4.02 \times 10^{-10}$ & & \\
\hline & $\mathrm{LiBF}_{4}$ & 0.090 & $8.72 \times 10^{-10}$ & $1.89 \times 10^{-8}$ & 14.0 \\
\hline & $\mathrm{LiNO}_{3}$ & 0.090 & $3.97 \times 10^{-9}$ & & \\
\hline & LiSCN & 0.090 & $4.42 \times 10^{-9}$ & $1.06 \times 10^{-7}$ & 13.9 \\
\hline & $\mathrm{LiCF}_{3} \mathrm{COO}$ & 0.090 & $2.53 \times 10^{-9}$ & & \\
\hline & $\mathrm{LiCF}_{3} \mathrm{SO}_{3}$ & 0.090 & $1.57 \times 10^{-8}$ & & \\
\hline & $\mathrm{NaBF}_{4}$ & 0.090 & $3.28 \times 10^{-9}$ & $7.88 \times 10^{-8}$ & 13.4 \\
\hline & $\mathrm{NaSCN}$ & 0.090 & $6.55 \times 10^{-9}$ & $4.80 \times 10^{-7}$ & 15.7 \\
\hline & $\mathrm{KSCN}$ & 0.090 & $1.14 \times 10^{-8}$ & $9.74 \times 10^{-7}$ & 15.9 \\
\hline PPO-3000 & & 0 & $<10^{-12}$ & & \\
\hline \multirow[t]{14}{*}{ Polycation } & $\mathrm{LiClO}_{4}$ & 0.010 & $2.64 \times 10^{-9}$ & & \\
\hline & & 0.015 & $4.50 \times 10^{-9}$ & $2.87 \times 10^{-8}$ & 8.4 \\
\hline & & 0.020 & $1.40 \times 10^{-8}$ & & \\
\hline & & 0.030 & $2.52 \times 10^{-8}$ & $3.38 \times 10^{-7}$ & 11.8 \\
\hline & & 0.040 & $4.21 \times 10^{-8}$ & $1.58 \times 10^{-6}$ & 14.2 \\
\hline & & 0.060 & $5.63 \times 10^{-8}$ & & \\
\hline & & 0.090 & $7.87 \times 10^{-8}$ & & \\
\hline & $\mathrm{LiBF}_{4}$ & 0.090 & $4.73 \times 10^{-9}$ & & \\
\hline & LiSCN & 0.090 & $2.57 \times 10^{-8}$ & & \\
\hline & $\mathrm{LiCF}_{3} \mathrm{COO}$ & 0.090 & $6.65 \times 10^{-9}$ & & \\
\hline & $\mathrm{LiCF}_{3} \mathrm{SO}_{3}$ & 0.090 & $1.00 \times 10^{-7}$ & & \\
\hline & $\mathrm{NaBF}_{4}$ & 0.090 & $8.13 \times 10^{-9}$ & & \\
\hline & $\mathrm{NaSCN}$ & 0.090 & $7.50 \times 10^{-8}$ & & \\
\hline & KSCN & 0.090 & $1.00 \times 10^{-7}$ & & \\
\hline PTMO-2000 & & 0 & $<10^{-12}$ & & \\
\hline Polycation & $\mathrm{LiClO}_{4}$ & 0.037 & $2.68 \times 10^{-9}$ & $4.83 \times 10^{-8}$ & 11.9 \\
\hline & & 0.054 & $3.84 \times 10^{-9}$ & $1.26 \times 10^{-7}$ & 14.0 \\
\hline & & 0.073 & $4.47 \times 10^{-9}$ & & \\
\hline
\end{tabular}


DDV-II direct reading dynamic viscoelastometer at $11 \mathrm{~Hz}$ from $-80^{\circ} \mathrm{C}$ to $50^{\circ} \mathrm{C}$. The rate of temperature change was maintaind at about $2^{\circ} \mathrm{C} \min ^{-1}$. The dimentions of the measured specimens were about $5 \times 20 \mathrm{~mm}$.

\section{$X$-ray Diffraction Patterns}

The X-ray diffraction patterns were measured with a Rigaku Denki 2026 diffractometer by a Cu$K \alpha$ line through a Ni filter over the diffraction angle

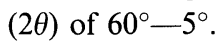

\section{RESULTS}

The components, composition and electrical properties of the polymeric solid electrolytes are summarized in Table II. The electrical conductivity $(\sigma)$ was calculated from the real resistance of the sample determined by the complex impedance diagram. Figures 3 and 4 show the relation between the reciprocal of the absolute temperature and the logarithm of the $\sigma$ value for the typical hybrid films. Since the relation was linear in the

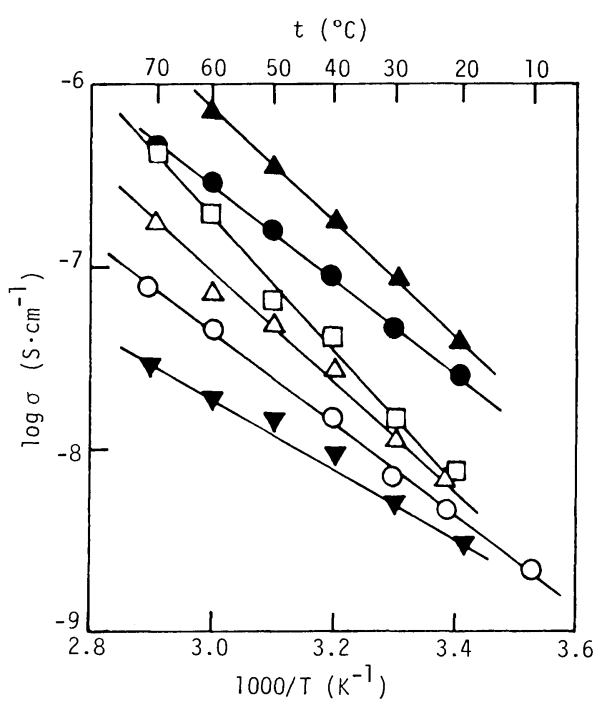

Figure 3. Temperature dependence of conductivity $\sigma$ for PPO polycation- $\mathrm{LiClO}_{4}$ hybrid films: $\mathrm{O}, \mathrm{PPO}-2000$ polycation $-\mathrm{LiClO}_{4}$ ([Salt $] /[\mathrm{PO}$ unit $\left.]=0.03\right) ; \triangle$, PPO2000 polycation- $\mathrm{LiClO}_{4}$ ([Salt $] /[\mathrm{PO}$ unit $\left.]=0.045\right) ; \square$, PPO-2000 polycation- $-\mathrm{LiClO}_{4}$ ([Salt $] /[\mathrm{PO}$ unit $]=0.09$ ); $\boldsymbol{\nabla}, \mathrm{PPO}-3000$ polycation $-\mathrm{LiClO}_{4}([\mathrm{Salt}] /[\mathrm{PO}$ unit $]=$ 0.015);, $\mathrm{PPO}-3000$ polycation- $\mathrm{LiClO}_{4}$ ([Salt]/[PO unit $]=0.03) ; \boldsymbol{\Delta}$, PPO-3000 polycation $-\mathrm{LiClO}_{4}$ ([Salt $] /$ $[\mathrm{PO}$ unit $]=0.04$ ). measured temperature range, the activation energy for conduction $\left(E_{\mathrm{a}}\right)$ listed in Table II was calculated from eq 3 ,

$$
\sigma=\sigma_{0} \exp \left(-E_{\mathrm{a}} / R T\right)
$$

where $R$ is the gas constant. The $\sigma$ at $20^{\circ} \mathrm{C}$ and $E_{\text {a }}$

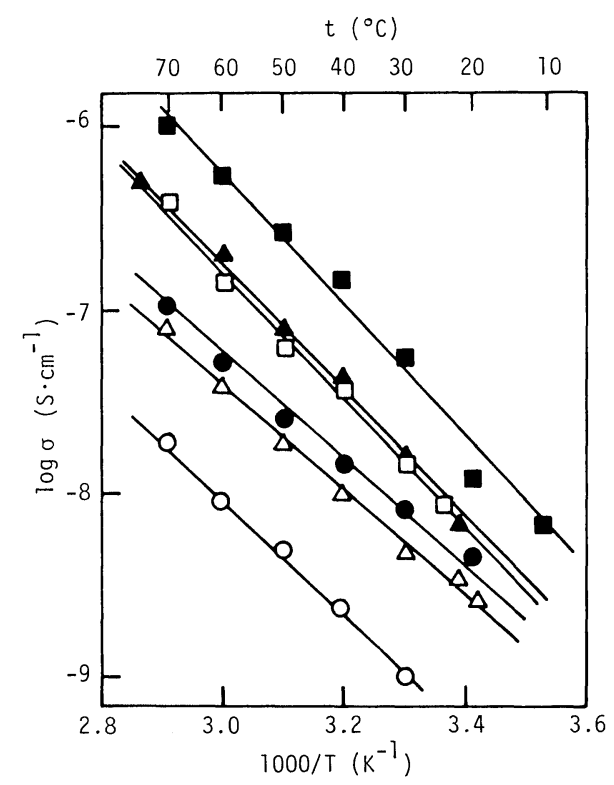

Figure 4. Temperature dependence of conductivity $\sigma$ of PPO-2000 polycation-salt hybrid films ([Salt]/[PO unit $]=0.09): \bigcirc, \mathrm{LiBF}_{4} ; \triangle, \mathrm{NaBF}_{4} ; \square, \mathrm{LiClO}_{4}$; LiSCN; $\boldsymbol{\Delta}, \mathrm{NaSCN} ; \mathbf{\square}, \mathrm{KSCN}$.

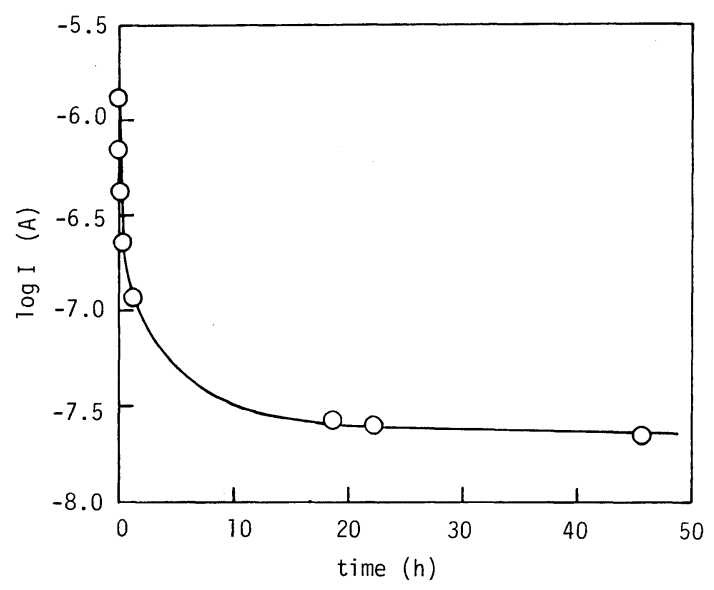

Figure 5. Change in current with time at $1.0 \mathrm{~V}$ through the polarization cell for PPO-3000 polycation- $\mathrm{LiClO}_{4}$ hybrid film $\left(\left[\mathrm{LiClO}_{4}\right] /[\mathrm{PO}\right.$ unit $\left.]=0.03\right)$. 
values were dependent on the type of polycation, the kind of salt and the salt concentration, changing from $10^{-7}$ to $10^{-10} \mathrm{~S} \mathrm{~cm}^{-1}$ and from 8 to $16 \mathrm{kcal}$ $\mathrm{mol}^{-1}$, respectively.

The $\sigma$ values of the polycation in the absence of salt were lower than $10^{-12} \mathrm{Scm}^{-1}$. The $\sigma$ values increased with the introduction of salts. The direct current through the polarization cell (2) decreased with time, and after $20 \mathrm{~h}$, reached a value corresponding to a conductivity of about $1 / 100$ of the initial conductivity, as shown in Figure 5. These results show that the hybrid films are predominantly ionic conductors. Thus, the $\sigma$ values listed in Table II represent ionic conductivity of the samples and are considerably high compared with those of ordinary ion-containing polymers in the absence of solvent. Consequently, hybrid films made from PPO or PTMO provide polymeric solid electrolytes with the ionic conductivity ranging from $10^{-7}$ to $10^{-10}$ $\mathrm{Scm}^{-1}$ at $20^{\circ} \mathrm{C}$.

\section{DISCUSSION}

\section{Dissolving State of Salts in PPO Based Polymeric Solid Electrolytes}

Figure 6 shows the temperature dependence of the storage elastic modulus $\left(E^{\prime}\right)$ and loss tangent $(\tan \delta$ ) for PPO-2000 and PPO-3000 polycations. The value of $E^{\prime}$ for the PPO-3000 polycation at $-80^{\circ} \mathrm{C}$ was of the order of $10^{10} \mathrm{dyn}^{\mathrm{cm}^{-2}}$ and dropped by about two orders of magnitude at about $-50^{\circ} \mathrm{C}$. It then showed a rubbery plateau level of about $10^{8} \mathrm{dyn} \mathrm{cm}^{-2}$ and dropped again at temperatures above $50^{\circ} \mathrm{C}$ to fluid state. The $E^{\prime}$ value for the PPO-2000 polycation also showed a rubbery plateau level. Thus, two mechanical relaxations were observed in the PPO polycations. Tan $\delta$ showed two peaks corresponding to the change in $E^{\prime}$. These observations are characteristic of thermoplastic elastomers with two phase system. Since the PPO polycations were found to be amorphous from the $\mathrm{X}$-ray analyses, the lower and higher relaxations are caused by micro-brownian motion of the PPO and polycation segments, respectively. ${ }^{12}$ It is considered that the PPO polycations form a phase-separated structure of the constituent segments. The polycation segments aggregate to form such domains as ionomers which exert crosslinking effects in the sample. ${ }^{12}$ The glass transition temperature $\left(T_{\mathrm{g}}\right)$ of the PPO segment in the PPO-3000 polycation was

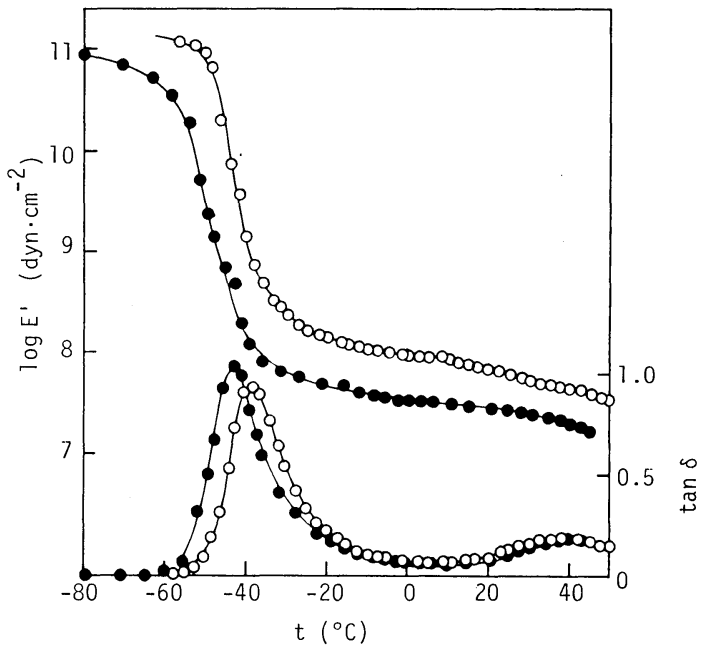

Figure 6. Logarithms of storage elastic modulus $\left(E^{\prime}\right)$ and loss tangent $(\tan \delta)$ at $11 \mathrm{~Hz}$ plotted against temperature: $\bigcirc$, PPO-2000 polycation; O, PPO-3000 polycation.

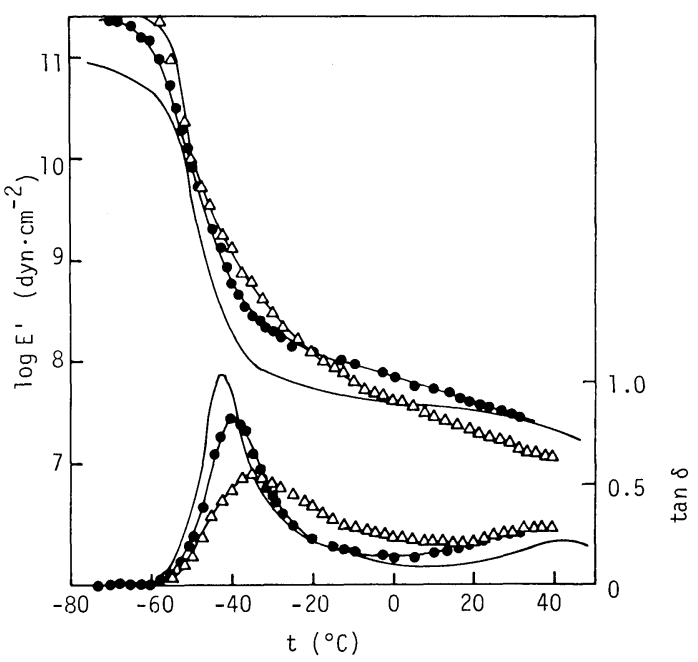

Figure 7. Logarithms of storage elastic modulus $\left(E^{\prime}\right)$ and loss tangent $(\tan \delta)$ at $11 \mathrm{~Hz}$ plotted against temperature: -, PPO-3000 polycation; O, PPO-3000 polycation- $\mathrm{LiClO}_{4}([$ Salt $] /[\mathrm{PO}$ unit $]=0.02) ; \triangle$, PPO3000 polycation $-\mathrm{LiClO}_{4}$ ([Salt $] /[\mathrm{PO}$ unit $]=0.03$ ).

lower than that in the PPO-2000 polycation, as shown in Figure 6. This may be caused by the ease of segmental mobility of the PPO segment in the PPO-3000 polycation, since both terminals of the PPO segment are fixed by the polycation segment 
domain.

All salts used were crystalline, showing many Xray diffraction peaks. However, the hybrid films were found to be amorphous from X-ray measurements indicating that the salts introduced into the films dissolve in the polycation matrix.

Dissolution of each salt changed the dynamic mechanical properties of the polycation matrix; that is, $T_{\mathrm{g}}$ of the PPO segment in the polycation increased with dissolving of each salt. Figure 7 shows representative behavior of this phenomenon in which the PPO- 3000 polycation is the matrix and $\mathrm{LiClO}_{4}$ is the dissolved salt. The $T_{\mathrm{g}}$ of the PPO segment in the salt free PPO-3000 polycation, as determined by the $\tan \delta$ peak, was $-43.2^{\circ} \mathrm{C}$. As the amount of dissolved $\mathrm{LiClO}_{4}$ increased, $T_{\mathrm{g}}$ also increased. When the [Salt]/[PO unit] reached 0.03 , the $T_{\mathrm{g}}$ was $-35.4^{\circ} \mathrm{C}$. It has been reported by Moacanin et $a .^{2}$ and Wetton et al. $^{3}$ that the interaction between salt and PPO containing ether oxygen atoms with strong affinity toward metal ions dissolved salt in PPO and increased its $T_{\mathrm{g}}$. The salts in this study thus dissolve in the PPO segment moiety of the polycation matrix through that interaction.

Effects of the dissolved salt on the enhancement in $T_{\mathrm{g}}$ of the PPO segment are divided into two classes. In one class, the effect was strong; $\mathrm{KSCN}$, $\mathrm{LiClO}_{4}, \mathrm{NaSCN}, \mathrm{LiSCN}, \mathrm{LiNO}_{3}$, and $\mathrm{LiCF}_{3} \mathrm{SO}_{3}$ belonged to this class. In the other class, the effect was weak; $\mathrm{KBF}_{4}, \mathrm{NaBF}_{4}, \mathrm{LiBF}_{4}, \mathrm{LiBr}, \mathrm{LiCl}$, and $\mathrm{LiCF}_{3} \mathrm{COO}$ belonged to this class. Figures 8 and 9 show typical dynamic mechanical properties of hybrid films containing different kinds of salt at the same concentration. The $T_{\mathrm{g}}$ of the PPO segment in the polycation matrix containing $\mathrm{LiBF}_{4}$ or $\mathrm{KBF}_{4}$ was about $-40^{\circ} \mathrm{C}$, but $0-10^{\circ} \mathrm{C}$ for hybrid films containing LiSCN or KSCN. This may result from the difference in the strength of interaction between the salt and PPO segment. Salts which interact strongly with the PPO segment increase the $T_{\mathrm{g}}$ considerably. On the other hand, weakly interacting salts with the PPO segment increase $T_{\mathrm{g}}$ only slightly.

\section{Effect of Salt Concentration on Electrical Properties of PPO Based Polymeric Solid Electrolytes}

Figure 10 shows the relation between salt concentration and the $\sigma$ values at $20^{\circ} \mathrm{C}$ for the PPO polycation- $\mathrm{LiClO}_{4}$ hybrid films. With an increase in

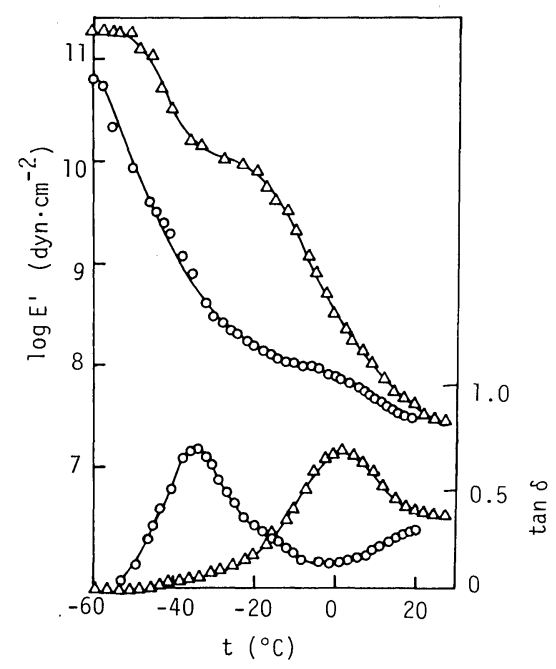

Figure 8. Logarithms of storage elastic modulus $\left(E^{\prime}\right)$ and loss tangent $(\tan \delta)$ at $11 \mathrm{~Hz}$ plotted against temperature: $\mathrm{O}, \mathrm{PPO}-2000$ polycation $-\mathrm{LiBF}_{4}$ ([Salt $] /[\mathrm{PO}$ unit $]=0.09) ; \triangle$, PPO-2000 polycation-LiSCN ([Salt]/ $[\mathrm{PO}$ unit $]=0.09$ ).

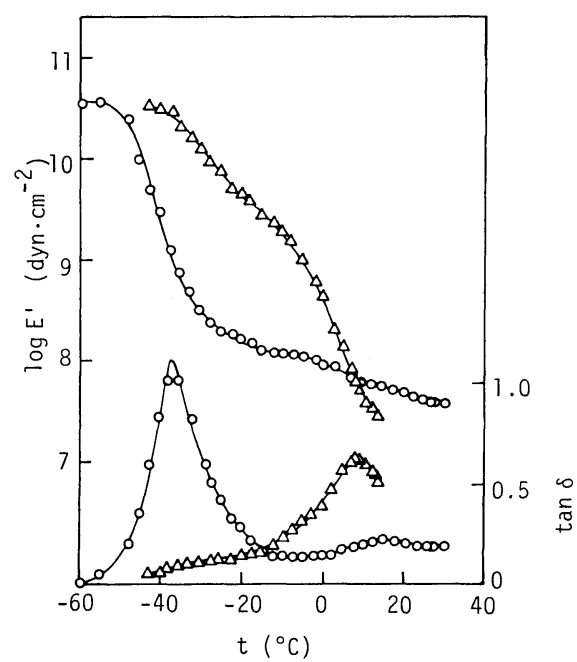

Figure 9. Logarithms of storage elastic modulus $\left(E^{\prime}\right)$ and loss tangent $(\tan \delta)$ at $11 \mathrm{~Hz}$ plotted aganist temperature: $\mathrm{O}, \mathrm{PPO}-2000$ polycation $-\mathrm{KBF}_{4}$ ([Salt $] /[\mathrm{PO}$ unit $]=0.09) ; \triangle$, PPO-2000 polycation-KSCN ([Salt $] /$ $[\mathrm{PO}$ unit $]=0.09$ ).

the $\mathrm{LiClO}_{4}$ concentration, $\sigma$ increases. $\mathrm{LiClO}_{4}$ dissolved in the hybrid films dissociates and generates carrier ions. The increase in the $\mathrm{LiClO}_{4}$ concentration enhances the number of carriers, resulting in 


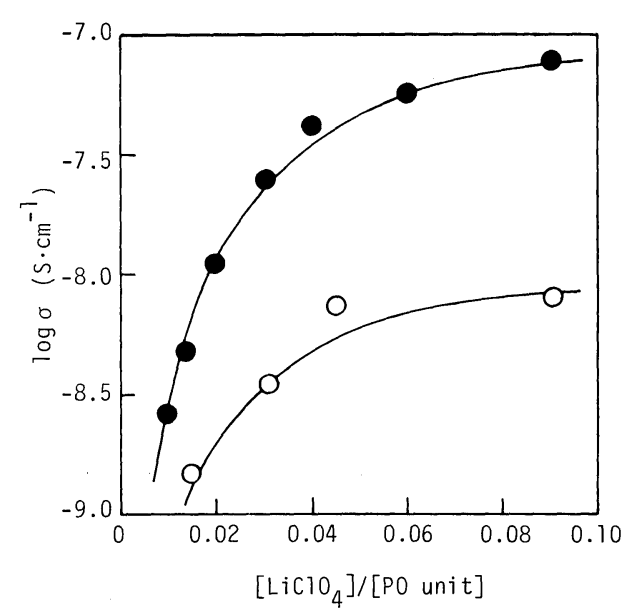

Figure 10. Relation between conductivity $\sigma$ and $\mathrm{LiClO}_{4}$ concentration for PPO polycation hybrid films: O, PPO-2000 polycation; $\mathrm{P}$, PPO-3000 polycation.

an increase in conductivity. When the $\sigma$ values are compared at the same $\mathrm{LiClO}_{4}$ concentration, the PPO-3000 polycation- $\mathrm{LiClO}_{4}$ hybrid films show higher conductivity than the PPO-2000 polycation$\mathrm{LiClO}_{4}$ hybrid films. The segmental mobility of the PPO segment in the PPO-3000 polycation is larger than that in the PPO-2000 polycation. Carrier mobility is dependent on the segmental mobility. ${ }^{13,14}$ Thus, the difference in the carrier mobility brings about the difference in the $\sigma$ values of two kinds of hybrid films.

The effects of salt concentration on the $E_{\mathrm{a}}$ values of the PPO polycation- $\mathrm{LiClO}_{4}$ hybrid films are shown in Figure 3. With an increase in the $\mathrm{LiClO}_{4}$ concentration, $E_{\mathrm{a}}$ increases. Little influence of the PPO segment size on the $E_{\mathrm{a}}$ values was observed. This indicates that the $E_{\mathrm{a}}$ values are largely dominated by ion-ion interaction. As the salt concentration increases, the relative distance between ions may decrease in the hybrid films, and the ionion interaction increases. Consequently, a larger $E_{\mathrm{a}}$ is necessary for ion conduction.

Effect of Salt Species on Electrical Properties of PPO Based Polymeric Solid Electrolytes

Figure 11 shows the relation between $1 /\left(r_{\mathrm{c}}+r_{\mathrm{a}}\right)$ and the $\sigma$ value at the same salt concentration, where $r_{\mathrm{c}}$ and $r_{\mathrm{a}}$ represent the cation and anion radius, respectively. The larger $1 /\left(r_{\mathrm{c}}+r_{\mathrm{a}}\right)$ value the salt has, the lower is the conductivity of the hybrid

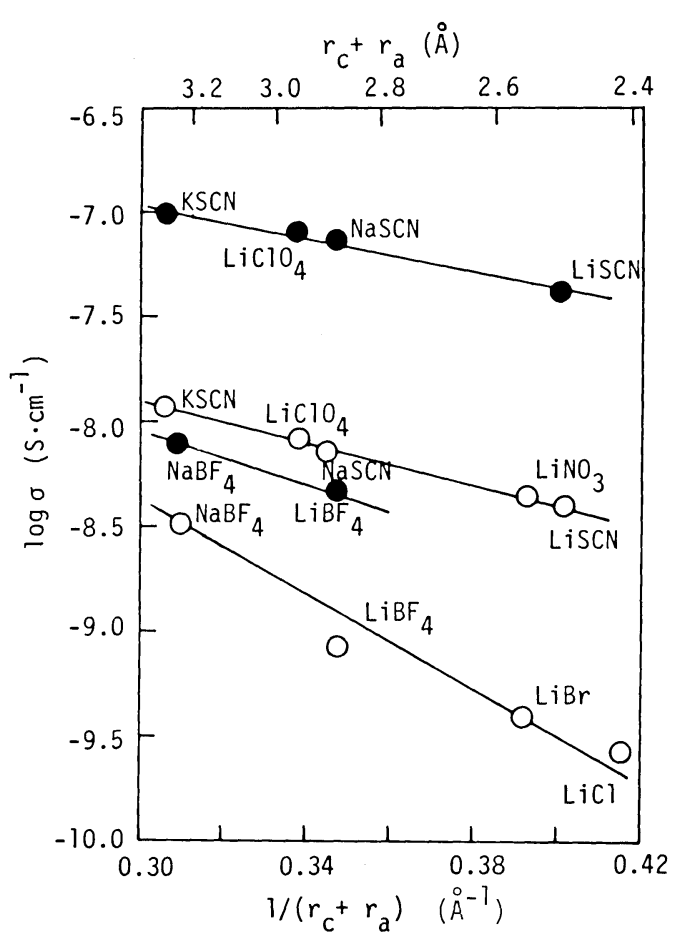

Figure 11. Relation between conductivity $\sigma$ and ion radius of salt in PPO polycation-salt hybrid films: $O$, PPO-2000 polycation; 1 PPO-3000 polycation.

films. The relation between $1 /\left(r_{\mathrm{c}}+r_{\mathrm{a}}\right)$ and the $\sigma$ value was divided into two classes, depend on the salt species. For the same salt species, the hybrid film based on the PPO-3000 polycation showed a higher conductivity than that based on the PPO2000 polycation.

Ionic conduction in polymeric solid electrolytes seems to result from hopping of carrier ions. The most stable hopping sites are considered to be ion site with the opposite charge of each ion. If one ion pair is formed in the process of ion hopping, the energy necessary for ion separation is shown in the following equation:

$$
\Delta E=\frac{e^{2}}{4 \pi \varepsilon_{0} \varepsilon} \cdot \frac{1}{r_{\mathrm{c}}+r_{\mathrm{a}}}
$$

where $e$ is the charge of the ion, $\varepsilon_{0}$ is the vacuum dielectric constant and $\varepsilon$ is the dielectric constant. Consequently, the $1 /\left(r_{\mathrm{c}}+r_{\mathrm{a}}\right)$ value of the salt can be a guide for the interaction between carrier ions in the polymeric solid electrolytes at the same salt concentration. As the $1 /\left(r_{\mathrm{c}}+r_{\mathrm{a}}\right)$ value decreases, the 
interaction decreases, resulting in an increase in $\sigma$.

The difference in the $\sigma$ values at the same $1 /$ $\left(r_{\mathrm{c}}+r_{\mathrm{a}}\right)$ value corresponds to the different effects of the salts on the increase in $T_{\mathrm{g}}$ of the PPO segment. The salt which causes a considerable increase in $T_{\mathrm{g}}$ of the PPO segment, belongs to the class in which a higher $\sigma$ value was observed. In contrast, the salt which increases slightly its $T_{\mathrm{g}}$, belongs to the other class in which a lower $\sigma$ value was observed. This difference in $\sigma$ values is caused by the difference in ion separation energy in the ion hopping process, that is, by the difference in the apparent dielectric constant around salts, since a compaison was made at the same $1 /\left(r_{\mathrm{c}}+r_{\mathrm{a}}\right)$ value in eq 4 . The salts which largely increase the $T_{\mathrm{g}}$ of the PPO segment are solvated sufficiently by the PPO segment through strong interaction between the salt and the PPO segment. This causes a large relaxation of the ion separation energy of the ion pairs. In such a case, the apparent dielectric constant seems large. The solvation of the PPO segment to the salts which slightly increase the $T_{\mathrm{g}}$ of the PPO segment is not sufficient. In this case, the relaxation of the ion separation energy is small, and the apparent dielectric constant seems small. From these results, the observed difference in $\sigma$ at the same $1 /\left(r_{\mathrm{c}}+r_{\mathrm{a}}\right)$ value is caused by the difference in the apparent dielectric constant around the salts due to the dissolving state of the salts in the polymeric solid electrolytes.

The dependence of the $\sigma$ value on the PPO segment size for hybrid films containing the same salt species is explained by the difference in the segmental mobility of the PPO segment.

The $E_{\mathrm{a}}$ values were not greatly influenced by the salt species and ranged from 13.4 to $16.2 \mathrm{kcal} \mathrm{mol}^{-1}$ at the same salt concentration. A clear dependence of the $E_{\mathrm{a}}$ values on $1 /\left(r_{\mathrm{c}}+r_{\mathrm{a}}\right)$ was not observed. Therefore, $1 /\left(r_{\mathrm{c}}+r_{\mathrm{a}}\right)$ values influence the preexponential factor $\left(\sigma_{0}\right)$ of eq 3 . Thus, $\sigma$ seems to depend on the $1 /\left(r_{\mathrm{c}}+r_{\mathrm{a}}\right)$ values.

\section{Effect of Polyether Segment Structure on Electrical Properties of Polymeric Solid Electrolytes}

The electrical properties of the PTMO based polymeric solid electrolytes are shown in Table II. A comparison was made of the electical properties of the PPO-2000 polycation- $\mathrm{LiClO}_{4}$ hybrid films and those of the PTMO-2000 polycation- $\mathrm{LiClO}_{4}$ hybrid films. At the same $\mathrm{LiClO}_{4}$ concentration, the $\sigma$ values of the PPO-2000 polycation- $\mathrm{LiClO}_{4}$ hybrid films were higher than those of the PTMO-2000 polycation- $\mathrm{LiClO}_{4}$ hybrid films, whereas the $E_{\mathrm{a}}$ values were similar to these hybrid films.

In the series of PPO based polymeric solid electrolytes, the segmental mobility of the PPO segment in the salt free polycation was a guide to carrier mobility. However, the difference in $\sigma$ values of the PPO-2000 polycation- $\mathrm{LiClO}_{4}$ and PTMO-2000 polycation- $\mathrm{LiClO}_{4}$ hybrid films can not be interpreted by the difference in the segmental mobility of the PPO and PTMO segments, since $T_{\mathrm{g}}$ of the PTMO segment $\left(-60.0^{\circ} \mathrm{C}\right)$ is lower than that of the PPO segment $\left(-37.8^{\circ} \mathrm{C}\right)$.

The reason for this may be the difference in the ion-polyether interaction of these hybrid films at the same salt concentration. There is a structural difference in these two polyether segments. Ether oxygen atoms with strong affinity toward metal ions exist between four carbon atoms in the main chain of the PTMO segment and two carbon atoms in that of the PPO segment. It has been reported ${ }^{3}$ that PPO favors the intramolecular dissolution of salts but PTMO does not favor the intramolecular dissolution of salts owing to entropical instability. Thus, the difference in the $\sigma$ values in the PPO based hybrid films and the PTMO based hybrid films is due to the difference in the dissolving state of $\mathrm{LiClO}_{4}$ for these two kinds of the polyether segments. This influences the pre-exponential factor $\left(\sigma_{0}\right)$ of eq 3 .

\section{REFERENCES}

1. E. Santaniello, A. Manzocchi, and P. Sozzani, Tetrahedron Lett., 47, 4581 (1979).

2. J. Moacanin and E. F. Cuddihy, J. Polym. Sci., C, 14, 313 (1966).

3. R. E. Wetton, D. B. James, and W. Whiting, J. Polym. Sci., Polym. Lett. Ed., 14, 557 (1976).

4. D. B. James, R. E. Wetton, and D. S. Brown, Polym. Prepr., Am. Chem. Soc. Div. Polym. Chem., 19, 347 (1978).

5. R. E. Wetton and D. B. James, Polym. Prepr., Am. Chem. Soc. Div. Polym. Chem., 19, 353 (1978).

6. M. J. Hannon and K. F. Wissbrum, J. Polym. Sci., Polym. Phys. Ed., 13, 113, 223 (1975).

7. M. Watanabe, J. Ikeda, M. Kanba, K. Nagaoka, E. Tsuchida, and I. Shinohara, Polym. Prepr. Jpn., 31, 752 (1982).

8. M. Watanabe, M. Kanba, H. Matsuda, K. Tsunemi, K. Mizoguchi, E. Tsuchida, and I. Shinohara, Makromol. Chem., Rapid Commun., 2, 741 (1981).

9. M. Watanabe, N. Toneaki, and I. Shinohara, Polym. J., 14, 189 (1982). 
M. WATANABE $e t$ al.

10. P. H. Bottelberghs, "Solid Electrolytes," P. Hagenmuller and W. V. Gool, Ed., Academic Press, New York, 1978, p 145.

11. C. Wagner, Z. Elektrochem., 60, 4 (1956).

12. M. Watanabe, Y. Takizawa, and I. Shinohara,
Polymer, in press (1982).

13. T. Miyamoto and K. Shibayama, J. Appl. Phys., 44, 5372 (1973).

14. H. Sasabe and S. Saito, Polym. J., 3, 624 (1972). 